\title{
Innovation in a Choice of Techniques Context: The Chinese Experience, 1958-1970
}

\author{
by Genevieve C. Dean*
}

Economic development in the People's Republic of China has been predicated on the basis of "technological dualism": the use of both modern, imported, large-scale, capital-intensive industrial technologies and of traditional, native, small-scale, 1abourintensive technologies, particularly in agriculture and consumer industries. These two economic sectors also coincide loosely with the State-owned sector of industry and the locally-owned sector provincial, county, special district, municipal and county enterprises. In both sectors, a process of technological innovation is expected to increase 1 abour productivity, bringing about development to higher levels of technology. For the modern sector, this may involve the adaptation of imported technology to suit production conditions in China, as well as the invention of original "high" technologies. The traditional sector is to develop through the gradual addition of labour-saving techniques. Although the tactics for technological development have varied over the past 22 years, the strategy has remained remarkably consistent. Equally, a critical problem has persisted as a constraint on the realization of policy: the development of a base of technical skills appropriate for innovation and development in the two sectors of technology. The persistence of this problem can be interpreted as a consequence of the institutional structure of the Chinese science and technology system - a structure and a problem shared by China with many developing countries.

The Great Leap Forward (1958-60)

The first Five Year Plan (1953-1957) emphasized capital construction and heavy industry in the State-owned sector, relying on the transfer of Soviet technology and technological know-how in 156 'key projects'. The supply of agricultural

* Genevieve C. Dean is a Research Fellow of the Science Policy Research Unit, University of Sussex. 
tools and equipment and of consumer manufactures had largely been left to locally-owned (i.e. by units below State level) industries and had been comparatively neglected in the Plan. By 1955/56, however, the unexpectedly rapid re-organization of agricultural production and the improvement of agricultural techniques envisaged in the Draft Progrom for Agricultural Development, 1956-1967 had generated demands for new technologies on a scale which could not be met by the locally-owned industries. In order to conserve state resources of investment capital and foreign reserves for the heavy industrial sector and to maintain the concentration of scarce scientific, technical and engineering skills in the capital goods and military sectors, while at the same time accommodating political and economic pressures for more productive agricultural and light industrial technologies, Chinese policy-makers encouraged a 'mass campaign for technological innovation' in the local, small-scale industries supplying consumer goods and agricultural equipment.

In May 1968, the Report of the Central Committee to the 8 th National Congress of the Chinese Communist Party stated the objectives of the new technology policy:

"To put the national economy, including agriculture and handicrafts, systematically and in a planned way on a new technological basis, i.e. the technological basis of modern, large scale production, so that machinery can be used wherever feasible and electrification is brought to all the cities and villages of the country".

But State investment in the modernization of the technological base of the national economy would be postponed for the immediate future:
"While introducing as far as possible the world's up-to-date techniques, to launch a widespread mass movement in the cities and villages throughout the country to improve tools and introduce technical innovations so that semi-mechanized or fully mechanized operations can be properly combined with the necessary hand work".

In the face of pressing demand for rapid economic growth and perceptible technological development*, this tactic was meant

* Note that the Central Committee's Report was presented by Liu Shao-ch'i, who has subsequently been identified with antithetical policies for economic and industrial development. 
to buy time, by diffusing rapid, although 1 imited, technological change as widely as possible, until the heavy industrial sector could provide modern capital equipment to the rest of the economy.

This 'cultural revolution' initiated a 'mass movement' for technological innovation. Inventions devised by workers on the basis of their practical experience would 'reform' and 'renovate' simple tools and equipment and eventually substitute machinery and the use of power for manual processes. The notion of 'mass innovation' stemed from the Marxist concept of technology as 'the summation of labour in action', the fruit of many years' practice by the working people'. Innovation, or change in production technology from a lower to a higher level of productivity, is the outcome of production experience - directly, through familiarity with existing technology, and indirectly, through knowledge of 'theory'. The purpose of the 'cultural revolution' was, to create social institutions which would tap this reservoir of experience.

The campaign for 'technological and cultural revolution' was, itself, an educational device which aimed to create a widespread awarenesss of the possibility and the benefits of technological change: "The masses now know that the conquest of nature is not a formidable task beyond their means". This awarenesss, in turn, created an impetus for technological modernization and a political force against technological conservatism. In the face of such political pressures, factory managers would be obliged to adopt 'mass innovations'; the greater these pressures, the more undiscriminating became the adoption procedure.

The source of 'mass' innovations is the worker's familiarity with the technology he uses, which enables him to recognize ways to change and improve it. The broader his own experience and his knowledge of other's experience, the greater his resources for making improvements. Historically, the development of separate institutions for production and for education had separated the 'two roads to invention and discovery', one starting from direct personal experience, the other from 'theory', or accumulated experience. The structure of social institutions built on this distinction, in the Chinese view, repressed invention based on experience, but also prevented theory science - from being applied to technological change. The 'cultural revolution' was an at tempt to close the gap by adding technical education to the worker's practical experience in order to expand his inventive capacity. Innovation, the use of new inventions, would in turn be facilitated by attendant 
improvements in the technical skills of the workers, who would operate and maintain the new and more complicated technologies and fulfill management and technical control functions. To this end, facilities for technical and scientific training after working hours were provided for workers by the factories where they were employed. By 1960, it was reported, 'an overwhelming majority' of enterprises had established spare-time training classes, technical schools, and universities, and 4.56 million workers had been enrolled.

The campaigns to improve the technical skills of the labour force, to popularize knowledge of elementary science, and to raise the scientific and technical qualifications of Party cadres were one aspect of the effort to integrate technological know-how with the actual operation of technology and control of technological change. The other aspect was an attempt to re-structure the social institutions which dominated science-based innovation. This institutional 'superstructure', in the Chinese view, enforced its control of technology and technological change - and thus its political position - by propagating the 'mystique' of science and the 'superstition' that technological change was impossible without the thoretical knowledge which it, alone, possessed. The 'cultural revolution' aimed, first, to break this monopoly on theoretical knowledge, and second, to find alternative sources of technological innovation.

Whatever the extent to which criticism of scientists and technicians stemmed from fear of the political power implied by their economic role - and the Hundred Flowers campaign only two years before had revealed the dissatisfaction of many intellectuals - the charges against them describe, in many respects, the syndrome of science in developing countries. Thus it is plausible that the attacks on Chinese scientists and technicians at this time were not motivated solely by political or ideological considerations, but stemmed from the specific failure of the scientific establishment to fulfill an economic function prescribed for it. The experience of other developing countries suggests, further, that the failure of science to play an economic role reflected the inadequacy of the institutional framework within which 'science' in developing countries operates.

Yet at no point did the Chinese absolutely deny the role of scientists and technicians in economic development. In 'mass' innovation, their function was to evaluate and select particularly 'advanced' experiences and 'raise them to the level of theory'; this presumably referred to the experimental develop- 
ment and testing of worker innovations in preparation for diffusing such innovations beyond the original point of invention. In fact, the re-emergence of scientists and technicians from political limbo, starting in 1961, was couched specifically in terms of the essential role of scientific and technical services in technological development.

The 'mass innovations' which were inspired by this campaign consisted of minor improvements to existing technology, substitution of locally available factors for scarce raw materials and intermediates, labour-intensive renovation and maintenance of outmoded and worn equipment, etc. The objective of the 'mass campaign', in other words, was to raise total output by inventing ad hoc techniques for the full exploitation of resources not usable in more productive industrial sectors. It was acknowledged that these techniques would have relatively low levels of productivity compared to modern, capital intensive technologies; nonetheless, they represented improvements over the levels attained with existing labour-intensive techniques. Mass campaigns in the previous two years had led to such wide-scale adoption of low productivity techniques that the new economic policies calling for a 'great leap forward in production' induced a labour shortage. 1 In the absence of substantial capital investment, which was not available on the scale required for nation-wide 'technological transformation', the answer, of necessity, was to raise total productivity in this sector through minor improvement innovations on existing capital stock.

The total addition to output which would result from widespread diffusion of limited technological change and from the mobilization of hitherto unused or underutilized resources was expected to offset whatever costs were incurred in order to achieve these minor improvements in productivity. Among the advantages claimed for 'native' innovations over 'foreign' technology were low initial investment costs, short time required for construction and installation, simplicity of operation and low skill requirements, and utilization of poor quality raw materials - all of these factors which would facilitate local investment in technological innovation, without requiring State resources. In effect, almost all opportunity costs to the development of the heavy industrial sector could thus be avoided.

\footnotetext{
1 It should be noted that, in the real world, technologies, once embodied in fixed capital, cannot easily be changed.
} 
Because the pattern of 'left-over' resources would vary from locality to locality, most of these innovations could not be standardized for diffusion beyond the point of original invention. What was to be diffused, therefore, was inventiveness and an innovative capability. This effort is seen, on the one hand, in the Central Committee's directive to establish research facilities at provincial, autonomous region, district and county level, and to establish regional branches of the Academy of Sciences. This so stretched 1 imited resources of professional scientific manpower, however, that within two years these plans had to be largely written off. On the other hand, experienced workers were encouraged to apply their practical knowledge to the improvement of familiar techniques.

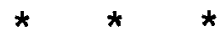

While the use of low-productivity technologies in smallscale industry did increase total output temporarily, this achievement was bought by concentrating all resources on production, at the expense of such 'non-productive' technical functions as maintenance and repair of equipment, product testing and standardization, etc. When the requirements of local, smallscale industry were permitted by political circumstances to intrude on the modern, State-owned sector, development of the less productive industries was halted, and many of the small plants were closed down or merged into large units, with workerinnovations either being discarded on technical grounds or taken up for further development by professional technicians and engineers. Because non-economic factors came to govern the allocation of factors of production between the two industrial sectors, the Great Leap experience is, ultimately, not a valid test of the choice of techniques mode. Nor does the Great Leap demonstrate the full innovative potential of small-scale, labour intensive technologies. Because institutional structures deprived this sector of specialized technical skills, the development of these technologies to higher levels of productivity was aborted. This, in turn, nullified one of the arguments used to justify innovation in small-scale industry: that limited technological innovation on the existing technological base promotes nondisruptive social change and creates new patterns in the organization of production which anticipate the eventual use of (capital-intensive) more productive technologies. This experience and the lessons learned from it are, I believe, the basis of innovation policies in China for the succeeding ten years. 
After the Great Leap

The basis of the new set of arguments was that, following the upsurge in output in the Great Leap Forward, priority should now be given to increasing the variety and improving the quality of products; and 'an increase in variety and improvement in quality are more dependent on a rise in the technical level than is an increase in the quantity of products'. Innovation in the course of production, 'mess' innovation, cen realize the potential of existing technology for higher productivity through modifications and improvements to capital equipment and processes already in use. But the invention of wholly new technologies was now asserted to be a specialized function, distinct from production.

Some of the consequences of technological change without scientific and technical services, such as were experienced in the 'mass' innovation campaign, may be inferred from the arguments now advanced in favour of technical specialisation. First, the enforcement of product standarda had been suspended as technical supervisory and evaluation facilities were devoted to production, and, in the all-out drive to raise production, goods of inferior quality had been included in output quotas. Now it was proposed that 'technical evaluation' be carried out at the design and trial manufacture stages as well as during production, and that consumer opinion be solicited. Secondly, production by small, uncoordinated units had resulted in the proliferation of specifications and standards, thus requiring specially-designed spare parts and accessories, wating designing capecity on special orders, and inhibiting multiple-use of goodo and mass production in general. Finally, maintenance and repair was neglected.

Therefore, it was argued, the 'front line', production, required the support of 'technical rear services', which included repair and assembly of equipment; measurement survey and tests; designing; inspection; research and experiment; and the collection of technical data and the maintenance of archives. Innovation, or 'development of new products', was among the technical services which support production. Innovation was now seen to involve research, experiment and design, trial manufacture, technical evaluation at the trial production stage, and reorganization of labour prior to mass production.

\section{The Role of Scientific and Technicel Services (STS)}

The Chinese interpretation of the economic function of 'technical rear services' seems to be based on a concept of contradiction between STS and short-term production increase; the 
role of STS is to 'consolidate' the production gains which are achieved by devoting all resources to increasing productivity. This concept leads to the notion of extraordinary periods when STS are suspended in order to concentrate all resources on increasing output, followed by periods when the increases are consolidated by 'technical evaluation': "Only when new achievements are made will technical evaluation be required. Under ordinary circumstances, therefore, technical evaluation always lags behind the emergence of new achievements and the trial manufacture of new products". In other words, if increases in production are to be more than ephemeral, testing, standardization, measurement, and maintenance functions must all be performed, in order to maintain the new levels of output.

STS were discussed in the context of modern industry in China; small-scale 'native' technology did not enter the discussions, and the concept of a 'choice' of technologies seems to have been dropped. Instead, it was emphasized that modern industries and technological modernization require STS.

A second difference between the policies of the previous three years and these arguments was the reversal of the order of priorities between 'practice' and 'theory' as a source of invention and innovation. Technology was now seen to be based on 'scientific and technical laws' rather than 'practice' or experience: technology is something larger than can be comprehended by the worker. The worker can devise improvements for that part of technology with which he is familiar but responsibility for technological change and development rests with specialized technical staff.

"Mass movements of technical innovation and technical revolution must be constantly launched in relation to production in industrial enterprises. Workers should be urged to make rationalization proposals, toward which enterprise leaders should adopt an attitude of active welcome. All proposals, the effectiveness of which has been confirmed by experiments, should be applied to production through definite procedures. This is an important aspect in promoting technical developments in industry. But the mass movements in technical work must be integrated with the strict technical control work, because modern industrial production continuously calls for a higher degree of organization and discipline. Regulations and systems concerning technical work ... are all important provisions for insuring normal production from the angle of technical order ... Technical regulations and systems 
are the summing up of technical theories, and there are many reasons for this, which cannot be quickly and entirely comprehended by the people doing the actual work. Hence there is the greater need to emphasize discipline and arbitrary practices must never be permitted."

Over the next 2 or 3 years, STS gradually re-emerged as a specialized activity in production, but there is a dearth of information from this period. Sometime in 1963 a 10 Year Plan for Science and Technology in Light Industry was prepared, but the details have never been published and its existence was not announced until 1965 when it had already been in force for $2 \frac{1}{2}$ years. Presumably in this Plan or at any rate at some time in this period, new institutional forms were introduced to sustain technological change. These were essentially new forms of linking existing institutions - i.e., integrating more closely the various stages of the innovation process, but still maintaining a functional distinction among them. Production, research, and training were linked together on the basis of permanent or semipermanent relationships among research institutes, factories and schools and, within production units, STS were performed by teams composed of technicians, workers and management cadres. Research and design were to be coordinated with production by involving designers in the trial manufacture and production stages of product development. Just what these various forms of 'triple combination' entailed is not clear; a reasonable guess is that with some few exceptions, a fair amount of formalism but relatively little substance characterized these arrangements. By 1966, the Vice Minister of the First Ministry of Machine-Building wrote in the People's Daily of the 'failure' of the practice of 'triple combination' during the previous few years. Nonetheless, the ' $3-i n-1$ ' team is the institutional form which still appears to dominate STS in Chinese factories, through the Cultural Revolution to the present day. The direction of Chinese technology policy since the inception of this form has probably been toward trying to make this institution function as prescribed. The 'failure' of the new institution occurred because it conflicted with the inherited patterns and values of conventional scientific and technical institutions.

Read in this light, the Cultural Revolution is seen as an effort to change those patterns and values, to substitute active comitment on the part of scientists to broad economic and social goals in place of 'science for science's sake'. The Cultural Revolution has not seen institutional innovations in the science and technology system as such, but rather, innovations in 
the way such institutions function. It cannot yet be said that the Chinese have developed an original model of scientific institutions; but what perhaps is unique in the Chinese model, certainly among developing economies, is the degree to which extra-scientific goals and objectives have penetrated the science system:

the degree to which the science system is being made to respond to the demands of the larger social system. 